\title{
Rigid polyurethane foam reinforced with cellulose whiskers: Synthesis and characterization
}

\author{
Yang Li', Hongfeng Ren² and Arthur J. Ragauskas ${ }^{1, *}$
}

A novel nanocomposite of rigid polyurethane foam was prepared by the polymerization of a sucrose-based polyol, a glycerol-based polyol and polymeric methylene diphenyl diisocyanate in the presence of cellulose whiskers. The cell morphology of the resulting foams was examined by scanning electron microscopy which showed both the pure foam and the nanocomposite foam had homogeneous cell dispersion and uniform cell size of approximately $200 \mu \mathrm{m}$. Analysis of the foams by Fourier transform infrared (FT-IR) spectroscopy indicated that both samples exhibited signals attributed to the polyurethane including the NH stretching and bending vibrations at $3320 \mathrm{~cm}^{-1}$ and $1530 \mathrm{~cm}^{-1}$, the $\mathrm{OC}=\mathrm{O}$ vibration at $1730 \mathrm{~cm}^{-1}$ and the $\mathrm{CO}-\mathrm{NH}$ vibration at $1600 \mathrm{~cm}^{-1}$. FT-IR analysis of the nanocomposite indicated that cellulose whiskers were crosslinked with the polyurethane matrix as the signal intensity of the $\mathrm{OH}$ stretch at $3500 \mathrm{~cm}^{-1}$ was significantly reduced in comparison to the spectral data acquired for a control sample prepared from the pure polyurethane foam mixed with cellulose whiskers. According to ASTM standard testing procedures, the tensile modulus, tensile strength and yield strength of the nanocomposite foam were found to be improved by $36.8 \%, 13.8 \%$ and $15.2 \%$, and the compressive modulus and strength were enhanced by $179.9 \%$ and $143.4 \%$, respectively. Dynamic mechanical analysis results testified the improvements of mechanical properties and showed a better thermal stability of the nanocomposite foam.

Keywords: Nanocomposites; Cellulose whiskers; Tensile; Compressive; Thermal

Citation: Yang Li, Hongfeng Ren and Arthur J. Ragauskas, "Rigid polyurethane foam reinforced with cellulose whiskers: Synthesis and characterization”, Nano-Micro Lett. 2, 89-94 (2010). doi: 10.5101/nml.v2i2.p89-94

Cellulose is one of the most abundant renewable materials in nature, representing about $1.5 \times 10^{12}$ tons of the total annual biomass production, and is considered a valuable bioresource for addressing society's increasing demand for environmentally friendly and biocompatible products [1]. It is composed of assemblies of microfibrils where the polymeric chains of $\beta$-(1,4)-D-glucose molecules are stabilized by inter- and intra-molecular hydrogen bonding. Upon acid hydrolysis, transverse cleavage happens primarily along the amorphous region of microfibrils, and under certain conditions release cellulose whiskers. These nanocellulose structures typically have a diameter on the order of 10 20 nm and a length of 100 300 nm when prepared from wood pulp or 1100 2000 nm long when derived from tunicates [2]. Cellulose whiskers exhibit a high bending strength of $10 \mathrm{GPa}$ and elastic modulus of $143 \mathrm{GPa}[3,4]$, and changes in electrical, optical, and magnetic properties with respect to the typical micron sized cellulose fibers [5]. There has been a growing interest in cellulose whisker-based composites with both natural and synthetic polymers as the matrix, in part, because of the improvements in the mechanical and thermal properties of the resulting nanocomposites [3,6-10].

Polyurethane (PU) is an important commercial polymer possessing a wide range of physical and chemical properties based on different combinations of starting materials [11]. Rigid PU foams are highly crosslinked polymers with a closed cell 
structure which are typically made from polymeric methylene diphenyl diisocyanate and polyols with hydroxyl index $\left(I_{\mathrm{OH}}\right)$ between 300 and 800 and viscosity below $300 \mathrm{~Pa} \cdot \mathrm{s}[12,13]$. Rigid PU foams offer low density, thermal conductivity, and moisture permeability properties along with high strength to weight ratio performance attributes. These properties have made PU one of the most common polymeric foam used on a global basis [14], which is reflected in its multitude of applications including ship-building, automotive, furniture, footwear, and packaging [15]. However, for such applications, rigid PU foams still present some disadvantages, such as low thermal stability and low mechanical strength [16]. Therefore, a substantial effort has been directed towards developing high performance rigid PU foams. Glycerol and cellulose fiber modified water-blown soy polyol-based PU foams were reported to have increased density and rigidity $[17,18]$. Rigid PU foams reinforced with spherical $\mathrm{TiO}_{2}$, platelet nanoclay, rod-shaped carbon nanofibers [19], and pristine and organically-modified layered silicates [14,20] have been investigated and shown to provide a significant enhancement of thermal and mechanical properties. However, to date, little work has been done on developing rigid PU foam reinforced with cellulose whiskers.

In the present study, we summarized the benefits of preparing a rigid $\mathrm{PU}$ foam reinforced with $0.75 \mathrm{wt} \%$ cellulose whiskers especially with respect to improvements in the mechanical properties of the resulting foam. Scanning electron microscope was used to characterize the cell structure of both foams. FT-IR spectroscopy was performed to study the chemical structure of these materials. Tensile and compressive properties as well as thermal stability were compared between the control foam and nanocomposite foam.

\section{Material and methods}

\section{Materials}

A commercial fully bleached softwood kraft pulp was used to prepare cellulose whiskers. Sulfuric acid (98 wt\%), neopentane, dimethylformamide (DMF) were purchased from VWR. Polymeric methylene diphenyl diisocyanate (MDI) with an average functionality of 2.7 and NCO content of $31.5 \%$ (Rubinate $\mathrm{M}$ ), sucrose-based polyol with a hydroxyl value of $356 \mathrm{mg} \mathrm{KOH} / \mathrm{g}$ polyol (Jeffol SD-361), glycerol-based polyol with a hydroxyl value of $246 \mathrm{mg} \mathrm{KOH} / \mathrm{g}$ polyol (Jeffol FX 31-240), dimethylcyclohexylamine (Jeff cat DMCHA), and 1-methyl-4- (2-dimethylaminoethyl) piperazine (Jeff cat TR-52) were all kindly provided by Huntsman Polyurethanes. Silicone surfactant (DABCO DC 5604) was obtained from Air Products and Chemicals, Inc. All chemicals were used as received.

\section{Preparation of Cellulose Whiskers}

Cellulose whiskers were prepared following a published method utilizing sulfuric acid [21]. In brief, softwood kraft pulp was ground in a Wiley mill to pass through a 20-mesh screen. Sulfuric acid (64 wt\%) and pulp in a ratio of $10 \mathrm{ml} / \mathrm{g}$ was reacted at $45^{\circ} \mathrm{C}$ for $45 \mathrm{~min}$ with strong mechanical stirring. The reaction was then halted by adding 10 -fold of deionized (DI) water. The sediment was centrifuged for $10 \mathrm{~min}$ at $12000 \mathrm{rpm}$ and the precipitate was collected, re-dispersed, and re-centrifuged twice. The product was dialyzed against DI water for 3 days using the regenerated cellulose dialysis tubing with a 12000 14000 molecular weight cut off until the $\mathrm{pH}$ of the solution reached 7. Sonication was performed to the neutral whiskers solution for $30 \mathrm{~min}$ while sitting in an ice bath. The colloidal suspension was centrifuged for $5 \mathrm{~min}$ at $5000 \mathrm{rpm}$ and the cloudy supernatant whiskers were collected and kept at $5^{\circ} \mathrm{C}$ prior to use.

\section{Preparation of the Pure Polyurethane Foam and Nanocomposite Foam}

A rigid PU foam was prepared following a one-shot method [22]. This procedure involved mixing certain amount of polyols (Jeffol FX 31-240 and Jeffol SD-361), neopentane, catalysts (Jeff cat DMCHA and Jeff cat TR-52), and surfactant (DABCO DC 5604) at $600 \mathrm{rpm}$ for $1 \mathrm{~min}$ as summarized in Table 1. Polymeric MDI was then added with stirring at 1500 rpm for $20 \mathrm{~s}$. After reacting for $3 \mathrm{~min}$, sufficient polymerization and crosslinking had occurred to solidify the foam. For preparation of the nanocomposite foam, freeze dried cellulose whiskers $(0.75 \mathrm{wt} \%$ of the total weight of polyols and Polymeric MDI) were first dispersed in DMF by sonication [6], and then polyols were added and mixed followed by removing DMF under reduced pressure. This mixture was employed in an analogous as described for the preparation of the control rigid PU foam. Both foams were cured at room temperature for $48 \mathrm{~h}$ before use [23].

\section{Characterizations}

The cell structures of the control and nanocomposite foam were examined under a field emission scanning electron microscope (LEO 1530 SEM). Samples were coated with gold palladium using EMS 350 sputter coating. SEM images were obtained using a $5 \mathrm{kV}$ accelerating voltage. FT-IR spectra of 
both foams were recorded between 4,000 and $600 \mathrm{~cm}^{-1}$ with a resolution of $4.00 \mathrm{~cm}^{-1}$ and 64 scans on a Magna 550 FT-IR spectrometer. Samples were prepared with $\mathrm{KBr}$ powder to obtain pellets with a $1 \mathrm{~mm}$ thickness.

\section{Physical Testing}

Tensile tests were performed on the Instron Corporation tensile testing machine 5566 according to ASTM D 638-08 using type IV specimen with dimension: thickness $=4 \mathrm{~mm}$, width $=6 \mathrm{~mm}$, gage length $=25 \mathrm{~mm}$. The crosshead speed was $5 \mathrm{~mm} / \mathrm{min}$. Compression tests were carried out with a 17-71 TMI Monitor/ Compression tester according to ASTM C 365M-05 on cylindrical specimens with dimension: diameter $=$ $30 \mathrm{~mm}$, height $=15 \mathrm{~mm}$. The crosshead speed was $6 \mathrm{~mm} / \mathrm{min}$. For each tensile and compressive data point, five specimens were tested, and the average value (ave.) was taken along with the standard deviation (S.D.).

\section{Thermal Mechanical Analysis}

Dynamic mechanical analysis (DMA) was carried out with a Q800 TA Instrument in tension clamps to determine the thermo mechanical response of the foams. The specimen was a rectangular strip with dimensions of $10 \times 6 \times 5 \mathrm{~mm}^{3}$. Measurements were performed at $1 \mathrm{~Hz}$ frequency. A temperature scan mode was used from room temperature up to $180^{\circ} \mathrm{C}$ with a heating rate of $2^{\circ} \mathrm{C} / \mathrm{min}$. The main relaxation temperatures associated with $T_{\mathrm{g}}$ were determined from the temperature position of the maximum in $\tan \delta$.

\section{Results and Discussion}

Two sensitive and important factors to make rigid PU nanocomposite foams are the presence of water and the dispersion of cellulose whiskers in the polymer matrix. As water can act as a chemical blowing agent due to the released carbon dioxide when reacting with isocyanates, its content in cellulose whiskers needs to be controlled. Hence, for this study cellulose whiskers were acquired by freeze drying. We chose neopentane as a physical blowing agent because of its general availability and reported benefits to the physical properties of the resulting foam [24]. Preliminary explorations demonstrated that using a well mixed suspension of cellulose whiskers in DMF resulted in improved dispersion of the whiskers in the polymer matrix. Based on the formulation described in Table 1, the reaction of polyols and polymeric MDI yielded the control foam with a density of $537.5 \pm 5.1 \mathrm{~kg} / \mathrm{m}^{3}$. Repeating the same experiment in the presence of $0.75 \mathrm{wt} \%$ cellulose whiskers provided a nanocomposite PU foam with a density of $535.9 \pm 3.3$ $\mathrm{g} / \mathrm{m}^{3}$.

Table 1. Formulation of the control rigid polyurethane foam.

\begin{tabular}{lr}
\hline Chemicals & $\mathrm{wt} \%$ \\
\hline Sucrose based polyols & 27.90 \\
Glycerol based polyol & 16.70 \\
Polymeric MDI & 40.60 \\
Dimethylcyclohexylamine & 1.30 \\
1-methyl-4-(2-dimethylaminoethyl) piperazine & 0.90 \\
neopentane & 11.20 \\
Silicone surfactant & 1.40 \\
\hline
\end{tabular}

Scanning electron microscope images of the control foam and nanocomposite foam reinforced with $0.75 \mathrm{wt} \%$ cellulose whiskers (see Fig.1) showed that the closed cells had homogeneous dispersion in the PU foams and the cell sizes were approximately $200 \mu \mathrm{m}$ for both samples. Cellulose whiskers did not alter the closed cell structure presumably because they can act as nucleation sites to promote the formation of fine cell structures [20].

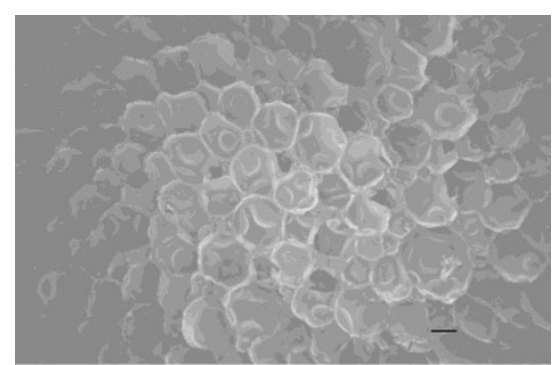

(a)

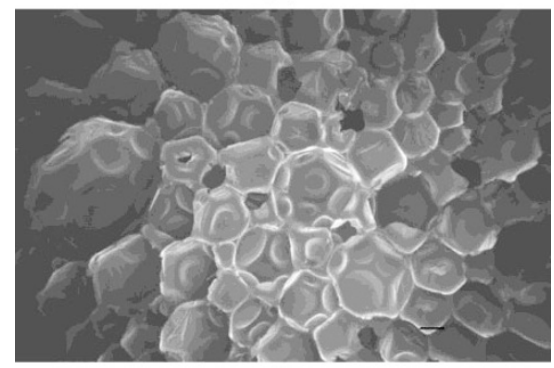

(b)

FIG. 1. SEM images of the control foam (a) and the nanocomposite foam (b) (Scale bar: $200 \mu \mathrm{m}$ ).

FT-IR spectroscopy was utilized to study the chemical structures of the control and nanocomposite foams (see Fig. 2). The presence of urethane linkages can be readily observed due to the $\mathrm{NH}$ stretching and bending vibration absorptions at $3320 \mathrm{~cm}^{-1}$ and $1530 \mathrm{~cm}^{-1}, \mathrm{OC}=\mathrm{O}$ vibration at $1730 \mathrm{~cm}^{-1}$, and CO-NH vibration at $1600 \mathrm{~cm}^{-1}$. Methyl group at $2930 \mathrm{~cm}^{-1}$, $\mathrm{O}-\mathrm{CO}$ at $1230 \mathrm{~cm}^{-1}$, and $\mathrm{C}-\mathrm{O}$ at $1090 \mathrm{~cm}^{-1}$ are from the polyether polyol and a small contribution of cellulose whiskers 
[3]. In order to investigate the interactions between the cellulose whiskers and the PU matrix with the nanocomposite, a spectrum of the control foam which was mechanically mixed with $0.75 \mathrm{wt} \%$ cellulose whiskers was recorded. Compared to the mixture of pure PU and cellulose whiskers, the nanocomposite foam shows a reduction in the intensity of the signal centered at $3500 \mathrm{~cm}^{-1}$ which is due to the cellulose O-H stretching vibration and N-H stretching vibration. The decreased signal intensity at $3500 \mathrm{~cm}^{-1}$ for the nanocomposite when normalized to the peak of the carbonyl group at $1730 \mathrm{~cm}^{-1}$ was attributed to the crosslinking of cellulose hydroxyl groups with isocyanate units during polyurethane synthesis.

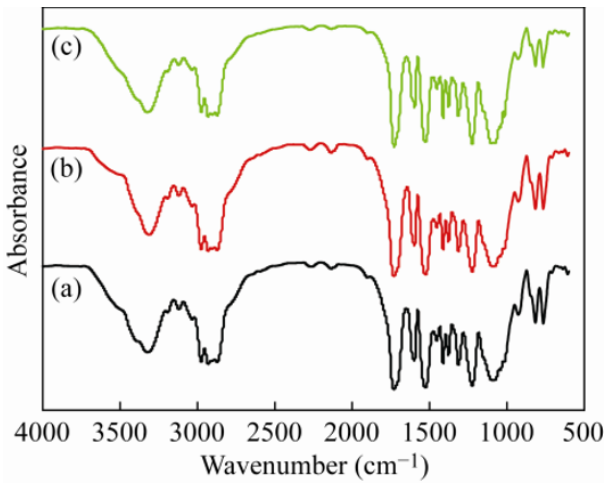

FIG. 2. FT-IR spectra of the control foam (a), the nanocomposite foam reinforced with $0.75 \mathrm{wt} \%$ cellulose whiskers (b), and a mixture of the control foam and $0.75 \mathrm{wt} \%$ cellulose whiskers (c)

Tensile stress-strain curves of the control PU foam and nanocomposite foam are shown in Fig. 3. The tensile properties are given in terms of tensile modulus, yield strength and tensile strength as summarized in Table 2. Polyurethane foam reinforced with $0.75 \mathrm{wt} \%$ cellulose whiskers has the same density as the control foam; however, it exhibited an increase in tensile modulus, yield strength and tensile strength by $36.8 \%$, $15.2 \%$ and $13.8 \%$, respectively.

Compressive stress-strain curves of the control foam and nanocomposite foam are shown in Fig. 4. The compressive properties in terms of compressive modulus and strength are summarized in Table 3. It is observed that with the same density, the modulus and strength of the nanocomposites are dramatically improved by $179.9 \%$ and $143.4 \%$, respectively. This substantial improvement in the compressive properties is accomplished at a much lower content of cellulose whiskers

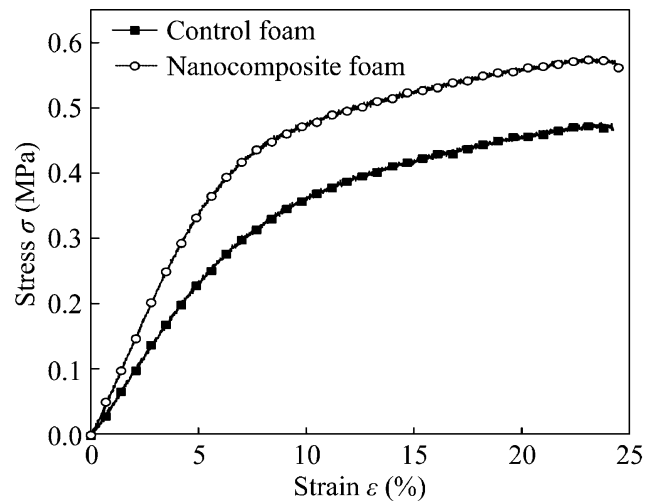

FIG. 3. Tensile stress-strain curves of the control foam and the nanocomposite foam.

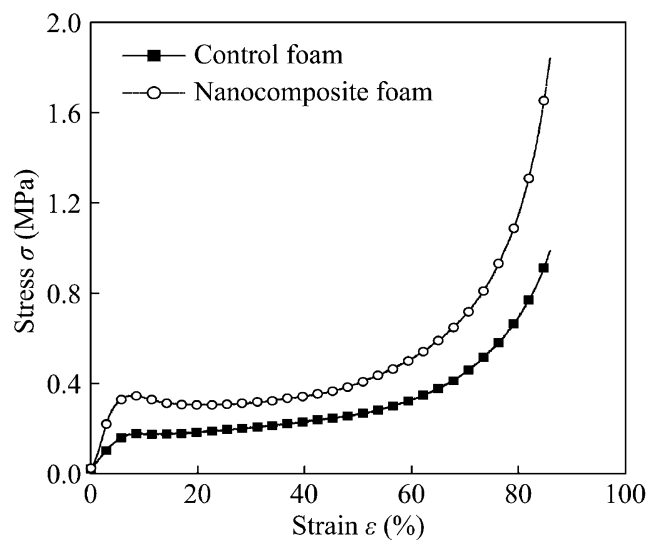

FIG. 4. Compressive stress-strain curves of the control foam and the nanocomposite foam.

than rigid PU foams reinforced with other inorganic nano particles up to $5 \mathrm{wt} \%$ [19].

There are several factors that can contribute to the mechanical improvements, especially the compressive properties. Cellulose whiskers have an intrinsic high bending strength of $10 \mathrm{GPa}$, high elastic modulus of $143 \mathrm{GPa}$ and high aspect ratio $[3,4,20]$, and those properties can undoubtedly enhance the mechanical properties of cellulose whisker/rigid polyurethane nanocomposite foam. The high specific surface area of cellulose whiskers may also contribute because of the chemical crosslinking between the cellulose whisker hydroxyl groups and the isocyanate groups. Finally, the improvement of mechanical properties of nanocomposites can also be attributed, in part, to the creation of multiple crack sites and/or branching due to the presence of nanoparticles into the polymer which

Table 2. Tensile properties of the control foam and the nanocomposite foam.

\begin{tabular}{|c|c|c|c|c|c|c|}
\hline \multirow{2}{*}{ Whisker (wt $\%)$} & \multicolumn{2}{|c|}{ Tensile modulus (MPa) } & \multicolumn{2}{|c|}{ Yield strength $(\mathrm{MPa})$} & \multicolumn{2}{|c|}{ Tensile strength (MPa) } \\
\hline & Ave. \pm S.D. & Gain $(\%)$ & Ave. \pm S.D. & Gain $(\%)$ & Ave. \pm S.D. & Gain $(\%)$ \\
\hline 0 & $4.37 \pm 0.41$ & - & $0.316 \pm 0.031$ & - & $0.485 \pm 0.043$ & - \\
\hline 0.75 & $5.98 \pm 0.37$ & 36.8 & $0.364 \pm 0.025$ & 15.2 & $0.552 \pm 0.015$ & 13.8 \\
\hline
\end{tabular}


Table 3. Compressive properties of the control foam and the nanocomposite foam

\begin{tabular}{ccccccc}
\hline Whisker & \multicolumn{2}{c}{ Compressive modulus (MPa) } & & \multicolumn{2}{c}{ Compressive strength (MPa) } \\
\cline { 2 - 3 } \cline { 5 - 6 }$($ wt $\%)$ & Ave. \pm S.D. & Gain (\%) & & Ave. \pm S.D. & Gain (\%) \\
\hline 0 & $3.29 \pm 0.58$ & -- & & $0.145 \pm 0.045$ & -- \\
0.75 & $9.2100 \pm 0.0004$ & 179.9 & & $0.353 \pm 0.007$ & 143.4 \\
\hline
\end{tabular}

delays the fracture processes in nanocomposites [19].

DMA is a thermal analysis technique that measures the properties of materials as they are deformed under periodic stress. Storage modulus, loss modulus and $\tan \delta$ can be directly given by the test while a variety of other fundamental material parameters can be defined from them such as glass transition temperature $T_{\mathrm{g}}$. In Fig.5 sumamrizes the typical DMA curves of storage modulus and $\tan \delta$ within a temperature range from $25^{\circ} \mathrm{C}$ to $180^{\circ} \mathrm{C}$. An abrupt diminution of the storage modulus, which relates to the mechanical failure of the material, can be observed. The appearance of a $\tan \delta$ peak which is so-called sample damping is associated with the material transition and is used historically in literature to define $T_{\mathrm{g}}$ [25]. The modulus value of the nanocomposite foam is significantly higher than the control foam at temperatures below $T_{\mathrm{g}}$. These results support the suggestion that the high mechanical strength of cellulose whiskers and the crosslinking introduced by whiskers
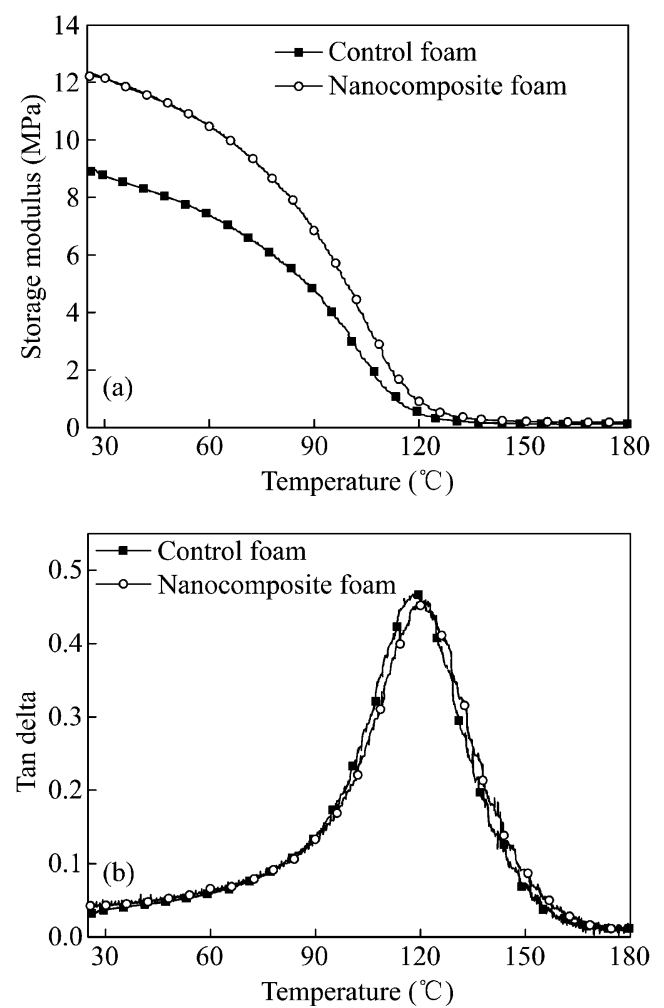

FIG. 5. Curves of storage modulus (a) and $\tan \delta$ (b) vs. temperature for the control foam and the nanocomposite foam. improves the mechanical properties of the rigid PU nanocomposite foam. It can also be observed that $T_{\mathrm{g}}$ values of the nanocomposite foam is a little higher than the control foam, which means a comparative or better thermal stability is achieved by the reinforcement of polyurethane with cellulose whiskers.

\section{Conclusions}

In summary, a rigid polyurethane nanocomposite foam reinforced with $0.75 \mathrm{wt} \%$ cellulose whiskers was prepared with homogeneous closed cell dispersion and uniform cell size. The improved mechanical properties and thermal stability of the nanocomposite foam provide a new and promising application of cellulose whiskers with an important synthetic polymer. Ongoing studies will further define the benefits of cellulose whiskers with synthetic and natural-based polyurethane foams.

The authors would like to acknowledge the financial support from the PSE Fellowship program at IPST@GT. The authors would also like to thank Rafael E. Camargo in Huntsman Polyurethanes for providing chemicals and advices.

Received 5 April 2010; accepted 6 May 2010; published online 13 May 2010.

\section{References}

1. D. Klemm, B. Heublein, H. P. Fink and A. Bohn, Angew. Chem. Int. Ed. 44, 3358 (2005). doi:10.1002/anie. 200460587.

2. J. G. Zhang, T. J. Elder, Y. Pu and A. J. Ragauskas, Carbohydr. Polym. 69, 607 (2007). doi:10.1016/j.carbpol. 2007.01.019.

3. X. D. Cao, H. Dong and C. M. Li, Biomacromol. 8, 899 (2007). doi:10.1021/bm0610368.

4. S. Harbaugh, N. K. Loughnane, M. Davidson, L. Narayanan, S. Trott, Y. G Chushak and M. O. Stone, Biomacromol. 6, 1055 (2005). doi:10.1021/bm049291k.

5. M. A. S. A Samir, F. Alloin and A. Dufresne, Biomacromol. 6, 612 (2005). doi:10.1021/bm0493685.

6. N. E. Marcovich, M. L. Auad, N. E. Bellesi, S. R. Nutt and M. I. Aranguren, J. Mater. Res. 21, 870 (2006). doi:10. 1557/jmr.2006.0105.

7. Y. Pu, J. Zhang, T. Elder, Y. Deng, P. Gatenholm and A. J. Ragauskas, Compos. Part B 38, 360 (2007). doi:10.1016/j. compositesb.2006.07.008.

8. M. A. S. A. Samir, F. Alloin, J. Y. Sanchez, N. E. Kissi and 
A. Dufresne, Macromolecules 37, 1386 (2004). doi:10.1021/ ma030532a.

9. M. O. Seydibeyoglu and K. Oksman, Compos. Sci. Technol. 68, 908 (2008). doi:10.1016/j.compscitech. 2007.08.008.

10. G. Siqueira, J. Bras and A. Dufresne, Biomacromolecules 10, 425 (2009).

11. D. Randall, S. Lee, The Polyurethanes Book, Huntsman Polyurethanes, Belgium, 2002.

12. C. A. Cateto, M.F. Barreiro, A. E. Rodrigues and M. N. Belgacem, Ind. Eng. Chem. Res. 48, 2583 (2009). doi:10.1021/ie801251r.

13. T. U. Patro, G. Harikrishnan, A. Misra and D.V. Khakhar, Polym. Eng. Sci. 48, 1778 (2008). doi:10.1002/pen.21145.

14. Z. B. Xu, X. L. Tang, A. J. Gu and Z. P. Fang, J. Appl. Polym. Sci. 106, 439 (2007). doi:10.1002/app.26497.

15. I. Banik and M. M. Sain, J. Reinf. Plast. Comp. 27, 357 (2008). doi:10.1177/0731684407083955.

16. X. Cao, T. Widy, C. Macosko and L.J. Lee, Polymer 46, 775 (2005). doi:10.1016/j.polymer.2004.11.028.

17. I. Banik and M. M. Sain, J. Reinf. Plast. Comp. 27, 1515
(2008). doi:10.1177/0731684407086317.

18. I. Banik and M. M. Sain, J. Reinf. Plast. Comp. 27, 1745 (2008). doi:10.1177/0731684407081442.

19. M. C. Saha, M. E. Kabir and S. Jeelani, Mat. Sci. Eng. A 479, 213 (2008). doi:10.1016/j.msea.2007.06.060.

20. M. Modesti, A. Lorenzetti and S. Besco, Polym. Eng. Sci. 47, 1351 (2007). doi:10.1002/pen.20819.

21. S. B. Candanedo, M. Roman and D.G. Gray, Biomacromolecules 62, 1048 (2005). $\quad \underline{\text { doi:10.1021/ }}$ bm049300p.

22. M. Thirumal, D. Khastgir, N. K. Singha, B. S. Manjunath and Y. P. Naik, J. Appl. Polym. Sci. 108, 1810 (2008). doi:10.1002/app.27712.

23. J. L. Rivera-Armenta, T. Heinze and A. M. Mendoza-Martinez, Eur. Polym. J. 40, 2803 (2004). doi:10.1016/j.eurpolymj.2004.07.015.

24. A. J. Birch. US Patent, 5451615, (1995).

25. E. A. Turi, Thermal Characterization of Polymeric Materials, Academic Press, New York, 1997. 